\title{
UNDERSTANDING PERCEIVED FLAMING TENDENCIES ON SOCIAL NETWORKING SITES: AN EXPLORATORY STUDY
}

\author{
Nitin, University of Nebraska at Omaha, Omaha, NE, USA, fnunitin@mail.unomaha.edu \\ Ankush Bansal, Associate Software Engineer, Accenture, INDIA, ankushbansal89@gmail.com \\ Deepak Khazanchi, University of Nebraska at Omaha, Omaha, NE, USA, khazanchi@mail.unomaha.edu
}

\begin{abstract}
Social Networking Sites (SNS) are getting an increasing user-base, with people of different socio-cultural and language backgrounds actively using these sites to interact with each other. The structure of these sites also enables users to befriend other users whom they have not met personally, through shared interests or activities making them 'non-met' friends. Computer mediated communication (CMC) such as SNS, Forums, Usenet, IRC etc. are characterized by flaming and with the increase in the user base on CMC, flaming is also on the rise. This increasing flaming has initiated debates and prompted concern whether CMC is favorable or disruptive for developing meaningful agreements between factions and whether CMC has positive or negative effect on society. Since SNS are becoming vital part of CMC, there is need to study about flaming in SNS. This exploratory study will help researchers to better understand the behavior of SNS users' towards flamed status messages and their flaming tendencies towards sensitive real life situations. The research adopted the method of surveying a small group of SNS users and studying the results to answer the research questions.
\end{abstract}

Keywords: Flaming, Social Networking Sites, Face to Face Communication, Computer Mediated Communication

\section{INTRODUCTION}

The internet has rapidly turned into a ubiquitous technology. One of its prime applications is in communication, termed more logically as Computer-Mediated Communication (CMC). It is used for two or more people interacting with one another to share information or knowledge using a computer as the medium of communication. This medium has been successful in bringing people from different cultural and social backgrounds to come together, interact and share their knowledge, opinions and ideas. This mode of communication can be characterized mainly by the presence of textual communication, which has little influence, or effect of non-verbal communication, physical separation and temporal flexibility [28].

Even though computer mediated communication is a medium to exchange information globally, there are some rules and etiquettes that are defined to ensure civility of interactions. Existing research suggests that different areas of CMC are characterized by intense language, swearing, negative or hostile communication [43]. Flaming, which is characterized by use of incendiary, hostile and profane language, texts and comments during a communication session, has been a part of all modes of communication but chances of flaming occurring during CMC are comparatively high [32]. Some research studies projected that these modes of communication invited more conflict through manipulative and disrespectful tendencies of users, which escalates anger and incites tensions between factions [13, 15, 23, 26, 30 and 33].

Social Networking Sites (SNS) were used to contact acquaintances, colleagues, friends and relatives but with the advances in web site design, people also started to interact with strangers through these sites. This led them to add such strangers as friends, making them "Non-met" friends. In addition, people who shared common interests or activities also got to become such "Non-met" friends through site features which encouraged discussions and debates. However, such discussions also incited flaming among users that hindered the process of sharing knowledge and thoughts. This defeat the purpose of these site features as people indulged more in flaming rather than healthy and beneficial discussions and debates. Therefore, through this study we are trying to find the flaming tendencies of the users and how they respond to it, which can be used in future to provide a better social networking environment. 
This exploratory study reports the results of flaming tendencies of people who are regular users on such sites by surveying and analyzing their behavior and response toward "flames". First, we will briefly introduce SNSs and then explain the notion of flaming and its occurrence in SNSs. Based on the survey results, we provide a discussion on flaming tendencies and behavior of the SNS users.

\section{SOCIAL NETWORKING SITES}

The advancement of technology and communication is now an integral part of human being's primal need "to be a social creature". Implicit in this statement is the idea that human beings have a need to interact with other individuals from his/her species for their well being. This is seen in the development of the internet, "A technology which connects people from different areas of the globe”.

Communication technologies expand human social circle $[10,17]$. SNSs used technological advancements to take advantage of human's above-mentioned need. These sites made it possible for individuals to stay connected with friends and relatives. A SNS is broadly defined as a web service that allows people

- To construct a self-authored identity of what they perceive of themselves (or called 'profile') within a structured framework.

- Define specifically a list of other users with whom they wish to share a connection with on the site, which is open to all the site users to view.

Social networking as a term is used to "initiate professional or personal friendship between people, some who are often strangers". This was not the trend when these sites were started [4, 9]. Previous research suggests that SNS users engage in searching for people whom they know in real lives more than they "browse and search" for complete strangers [22]. With the advent of venues on these sites for group discussions, communities for common interests and tastes, people are networking in its true sense. They often 'befriend' others who share common interests, activities, likes or dislikes, passions, etc for having valuable and constructive discussions on them, which they are seldom able to do with friends they know personally. Early research on online communities assumed that people connecting on them 'befriend' others outside their pre-existing social group or location, thus allowing them to form communities and groups more around shared interests rather than by geographical affinity [27, 45].

\section{FLAMING}

Computer Mediated Communication (CMC) has been credited with increasing the user base, both in communication volume and diversifying the groups of people who are involved in decision making [18, 20], reducing the need for physical presence for interaction also saving timing [11], and increasing communication across horizontals and verticals in the organization [16]. However, flaming has prompted concerns and debates about whether CMC is favorable or disruptive for developing meaningful agreements between factions and whether it has a positive or a negative effect on society.

Various researchers have attempted to define and characterize flames using short definitions. Some of them being “incendiary messages" [41], "rude or insulting messages" [37], "Inflammatory remarks" [3], "vicious attacks" [8] "vitriolic online exchanges or poison pen letters". Typical descriptions that have been used for flaming are "Scathingly critical personal messages or remarks", "Nasty and often profane diatribe" [6], "use of overheated prose" [40], "brusque putdowns, off color puns, anonymous gripes and derisive commentary" [41], "Derogatory, obscene or inappropriate use of language" [38]. Tamosaitis [41] strongly suggested that flames were "nonconstructive criticism or an overheated debate" but no definite and complete definition has been proposed for flaming as of date. Most researchers and analysts agree that flaming can be called an intentional act that occurs via computer-mediated communication channels. There is also agreement that flaming is predominantly used when individuals assert their eminence or expertise in a certain topic and is reciprocated by disagreement, jest, immaturity or perceived baseless banter.

Moreover, earlier research suggests that flaming may be the result of demographic (e.g., gender, age, culture), psychological (e.g., external locus of control, creativity, ideas), and behavioral variables (e.g., an idea or intuitive feeling that one' vested interests are at stake or is going to be sacrificed) [21]. Lea and associate suggested that 
occurrence of flaming in CMC depends on social influence of a group on an individual [24] and how he identifies himself with the social norms affects his communication [19]. Research has also shown that males have a greater tendency to flame than female participants [1]. Other researchers explained that to flame is a behavioral tendency and caused by hostility [31,35] or by psychological tendencies affected by uninhibited behavior resulting from two subjective states of one's perception - public versus private self-awareness [29, 34].

\section{FLAMING IN FACE-TO-FACE COMMUNICATIONVERSUS COMPUTER MEDIATED COMMUNICATION}

Face to face communication and CMC can be used to discuss any topic but there are notable variations due to the medium of communication. Due to physical presence, which is an important factor of inhibiting volatile behavior, factions restrict themselves to be assertive. Such "conversations occur in a cooperative environment constantly regulated by mutual adjustment and correction" [14]. It is also generally noted that in face-to-face communication, when there is a "heated topic of discussion", factions tend to speak simultaneously or together at varying loudness of voice using animated gestures and body language. Individuals show lesser inhibitions when communicating as a group [5]. In any moderated discussion, the factions are to abide by the rules laid down by the moderator to avoid flaming. Restricted or mild flaming is only seen in extreme cases, which are often rebuked with warnings. In unmoderated discussions, flaming is more prevalent, but factions who desire to have a meaningful discussion with a common consensus to the discussion often avoid flaming as it inhibits the drawing of a reasonable conclusion.

Initial research comparing CMC and face-to-face communication [20,39] showed that flaming and other antisocial interactions, incendiary messages; hostile comments were more common in electronic interactions. Since its inception, CMC has been perceived as having the same modes and rules of face-to-face communication would be directly applicable. As the user base grew, the differences and innate properties of the medium of communication were discovered. For example in CMC, the sizes of sentences or 'utterance' are generally short in length [7]. In synchronous CMC, user's utterance is organized by the medium (software) as per who entered the utterance first in real time, as registered by the medium, after which it is displayed to other users in the same order, though sequential utterances is not a mandatory for a meaningful conversation to take place. It is to be noted that, in most CMC setups, and specifically, in asynchronous CMC environments, two innate features of face-to-face conversation are absent"the collaborative commitment of factions and the co-formulation of the utterances" and "the feedback process, which permits social meaning of the message delivered to be processed quickly" [7, 25].

Landry [23] and other scholars argue that the depersonalization of the participating factions and the lack of social cues which are generally found in face-to-face communication but absent in CMC, hence creating misunderstandings between communicators, which present situations that lead to flaming behavior [2, 33, 44]. However, in SNSs the users mostly know each other while in some cases may be mere acquaintances or 'never-met' but still have the liberty of viewing and replying in each other's profile pages. On forums and message boards, where a large majority do not know each other personally but still interact due to their common interest, cases of flaming is more uninhibited since the 'flamers' feel there would a little real life retribution for their actions on such platforms.

Our research centered upon the following research questions:

$\mathrm{RQ}_{1}$ : Do SNS users prefer to post a high flamed message as their own "Status Message" for a given situation?

$\mathrm{RQ}_{2}$ : Do SNS users respond to a high flamed message posted by a "non-met” friend?

\section{METHODOLOGY}

In order to answer the research questions, we surveyed a sample of users from different SNS like Facebook, Orkut, and MySpace etc. The participating subjects were asked to complete a survey consisting of three sections. The first section elicited demographic details such as age, gender, number of friends, number of 'Non-Met' friends and period of activity on at least one SNS. 
Volume XII, No. 1, pp. 425-435, 2011

The second section presented the subjects with two different sensitive and real life situations. Each of the situations put forth five different status messages with varying level of flaming. Every subject was asked to choose one of the status messages corresponding to the situation, which they would be willing to put up as their own status message. This section also included rating the flaming level of each of the messages as per their personal discretion based on a "Flaming Invective Scale”, where ' 1 ' represented 'least flamed' and ' 5 ' represented 'most flamed'. The "Flaming Invective Scale" was developed by Turnage [42] and is a semantic differential scale measuring responses on two different situations that consist of five corresponding status messages each. The scale assesses the general level of flames for each status message in the scenarios provided. The idea behind this was to know the tendencies of the subject towards a flamed status message with respect to all other subjects and on what level of flaming would they choose in their own status messages.

The third section presented a flamed status message along with a hypothetical situation that such a status message was posted by one of their 'Non-Met' friends. The subjects were asked to consider this situation and present their reaction particularly whether they would reply to such a message with any level of flaming or not. They were not aware about the mean flaming level of the status message. It was their own opinion whether they would consider message highly flamed or less.

\section{Participants}

The study sample consisted of 70 subjects, which were chosen randomly from different cultural and social backgrounds. All the 70 subjects were users of one or more SNSs for duration of 1 year and above.

\section{RESULTS}

Survey - Section 1

The results of section 1 showed that the study sample consists of $58.57 \%$ males (41) and $41.43 \%$ females (29) who are from different age groups as illustrated in the following Table 1 and have mean of 266.67 friends in their respective friend list. All subjects were also asked to give the number of 'Non Met' users in their friend list. This generated a mean percentage of $12.127 \%$ (32.34) friends whom the subjects had accepted as friends but never met in person ('Non-Met' Friends).

Table 1. Demographic details of the subjects

\begin{tabular}{|c|c|c|c|c|}
\hline Age Group (in yrs) & Male & Female & Number of Subjects & Percentage (\%) \\
\hline 20 to 30 & 30 & 14 & 44 & 62.857 \\
\hline 30 to 40 & 5 & 7 & 12 & 17.143 \\
\hline 40 to 50 & 3 & 3 & 6 & 8.571 \\
\hline Above 50 & 3 & 5 & 8 & 11.428 \\
\hline & & & Total $=70$ & Total = 100 \\
\hline
\end{tabular}

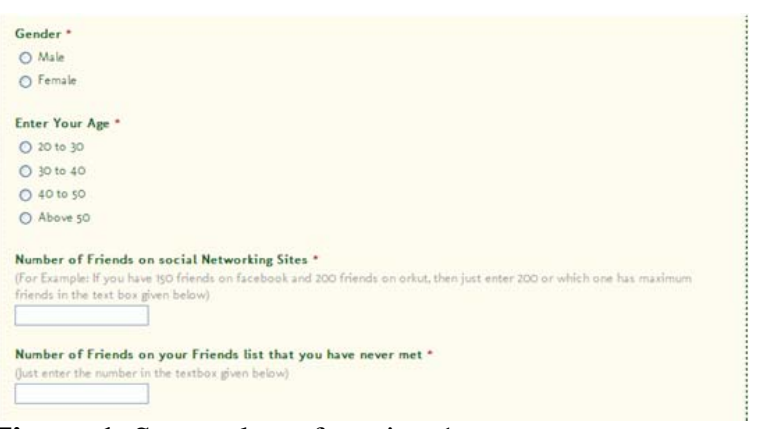

Figure 1. Screenshot of section 1 
Volume XII, No. 1, pp. 425-435, 2011

Survey - Section 2

In section two of the survey (as discussed earlier); the following real-world situations were presented to the survey subjects.

Situation 1: During the final of the 2006 FIFA World cup (Soccer), Italian defender Marco Materazzi and French mid-fielder Zinedine Zidane briefly exchanged words. Moments later, Zidane suddenly stopped, turned around and rammed his head into Materazzi's chest, knocking him to the ground. Zidane was given a red card for this. The match later went to penalty shootouts, in which France lost the cup.

These were the various status messages that were presented with the above situation:

Status 1: "The only way Italians can win the cup is to get their opponents Red Carded. It's a team which has no spirit of the game".

Result: This message had an average rating of 3.214. Only 18.58\% (Number $=13$ ) of the subjects selected this message.

Status 2: "The one who loses his cool loses the game in the end - the best example being the FIFA final".

Result: This message had an average rating of 1.777 . Majority of subjects chose this as their status message. On statistical grounds, $58.57 \%$ (Number $=41$ ) of the subjects selected this message.

Status 3: "Zidane is a fool to lose his cool like that, regardless of non sportsman like behavior of the Italians; he should have focused in the game and played for his country”.

Results: This message had an average rating of 1.96. Around 11.43\% (Number=8) of subjects selected this message. Status 4: "Materazzi and Zidane are big time@\$\$\#\&@\$”.

Results: This message had an average rating of 3.46. About 5.71\% (Number=4) of the subjects selected this message.

Status 5: Materazzi and Zidane have disgraced the game. The Result was only pure chance”.

Results: This message had an average rating of 2.271. Around 5.71\% (Number=4) of the subjects selected this message.

Table 2. Standard Deviation and Mean Flaming Rating of Status Messages for Situation 1

\begin{tabular}{|c|c|c|c|c|}
\hline Status & Mean & Standard Deviation & Low & High \\
\hline Status 1 & 3.214 & 1.61 & 1 & 5 \\
\hline Status 2 & 1.77 & 0.89 & 1 & 5 \\
\hline Status 3 & 1.96 & 1.15 & 1 & 5 \\
\hline Status 4 & 3.46 & 1.55 & 1 & 5 \\
\hline Status 5 & 2.271 & 1.17 & & 5 \\
\hline
\end{tabular}

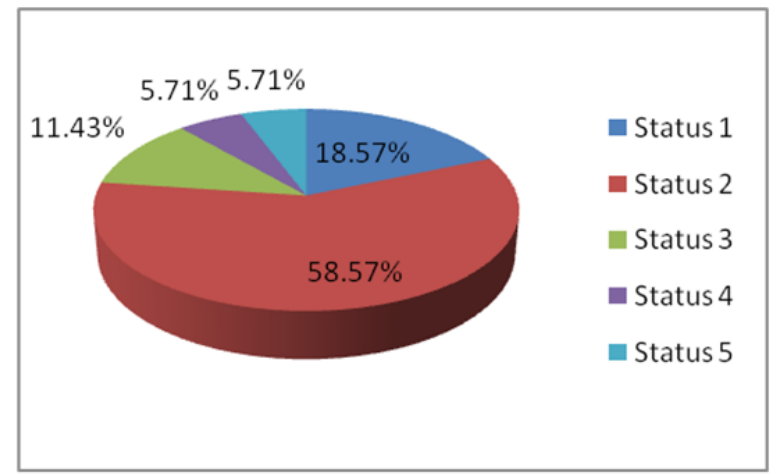

Figure 2. Percentage of Subjects Choosing a Status (Situation 1) 
Volume XII, No. 1, pp. 425-435, 2011

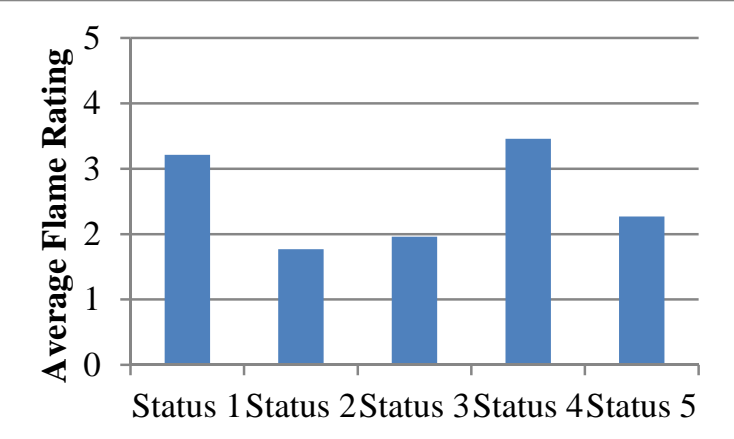

Figure 3. Mean Flaming Rating of Status Messages (Situation 1)

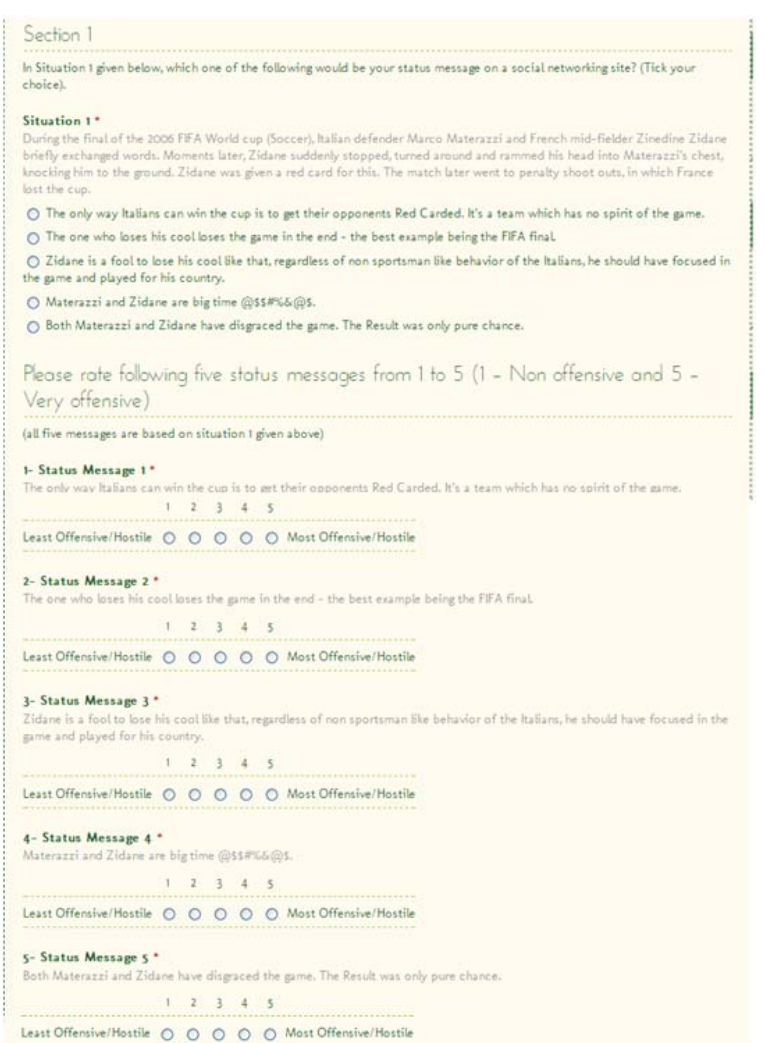

Figure 4. Screenshot for section 2 (situation 1)

Situation 2: The Copenhagen Summit 2009 was organized to decide on a collective decision that the world countries would take to deal with the changing climatic conditions of the world. The summit ended in an overall failure with countries only "taking note of" the changes they were to make in their national policies and not "adopting" them. The countries were not willing to sacrifice their own industrial development for the sake of keeping the earth's climate sustainable for the human race.

These were the various status messages that were presented with the above situation:

Status 1: "The world is doomed. Our governments are to be blamed for that. For the sake of a few bucks, we are dropping the axe on our necks".

Result: This message received an average rating of 2.24. Around 18.58\% (Number $=13$ ) of the subjects selected this as their status message. 
Volume XII, No. 1, pp. 425-435, 2011

Status 2: "The Developed countries (U.S, U.K, etc) contribute more towards global development and deserve higher upper limits to pollution emission".

Result: This message received an average rating of 2.34. About 22.86 (Number=16) of the subjects selected this as their status message.

Status 3: "Instead of killing us slowly why don't these $\mathrm{f}^{* * *}$ ers just drop a bomb on us all and get it over with".

Result: This message received an average rating of 2.857. Majority of subjects chose this as their status message. On statistical grounds, 42.85 (Number $=30$ ) of the subjects selected this message.

Status 4: "U.S, European union and other developed countries are to be blamed for this. They should suck it up and clean up their mess. Not push it to the developing countries and then blame them".

Result: This message received an average rating of 2.52. Around 10\% (Number=7) of the subjects selected this as their status message.

Status 5: "Just some morons trying to say that they care about this $\mathrm{f}^{* *} \mathrm{k}^{* *} \mathrm{~g}$ world. But only thing they care is about themselves and their $\mathrm{f}^{* *} \mathrm{k}^{* *} \mathrm{~g}$ money".

Result: This message received an average rating of 3.014. Around 5.71\% (Number=4) of the subjects selected this as their status message.

Table 3. Standard Deviation and Mean Flaming Rating of Status Messages for Situation 2

\begin{tabular}{|c|c|c|c|c|}
\hline Status & Mean & Standard Deviation & Low & High \\
\hline Status 1 & 2.24 & 1.31 & 1 & 5 \\
\hline Status 2 & 2.34 & 1.46 & 1 & 5 \\
\hline Status 3 & 2.857 & 1.61 & 1 & 5 \\
\hline Status 4 & 2.52 & 1.34 & 1 & 5 \\
\hline Status 5 & 3.014 & 1.63 & 1 & 5 \\
\hline
\end{tabular}

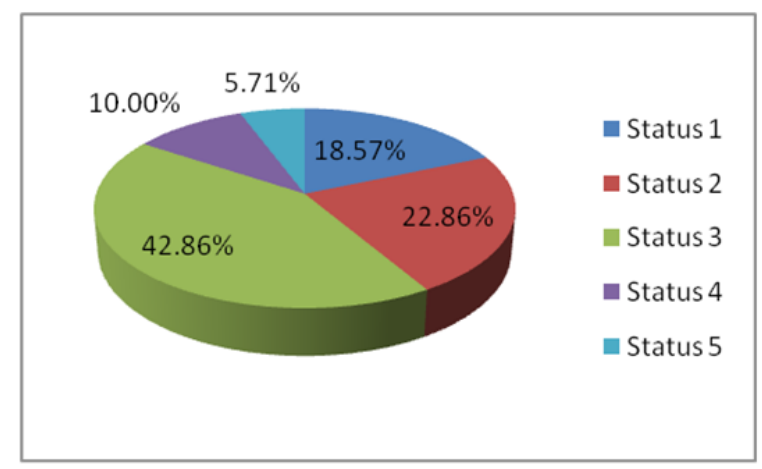

Figure 5. Percentage of Subjects Choosing a Status (Situation 2)

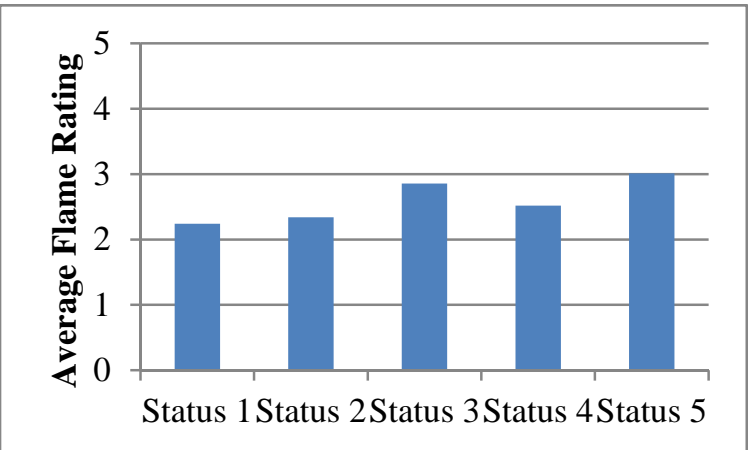

Figure 6. Mean Flaming Rating of Status Messages (Situation 2) 
Volume XII, No. 1, pp. 425-435, 2011

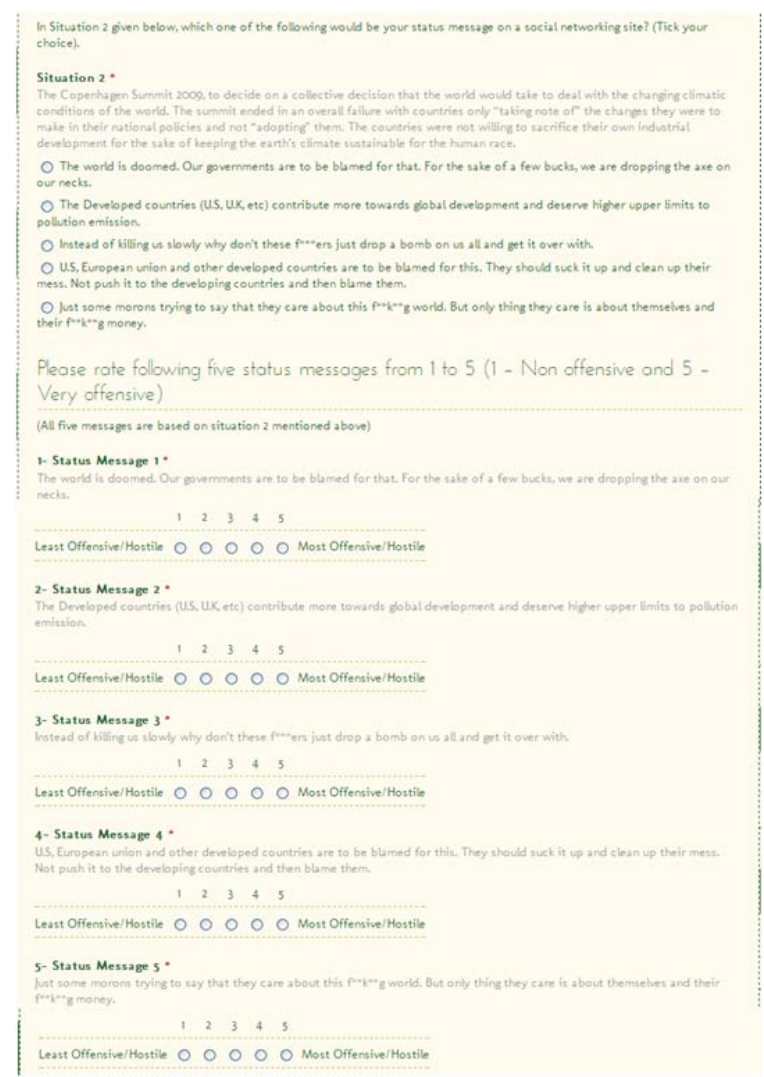

Figure 7. Screenshot of Section 2 (Situation 2)

Survey - Section 3

The following Status message was presented to the subjects based on situation 1 given in section 2:

"The only way Italians can win the cup is to get their opponents Red Carded. It's a team which has no spirit of the game.”

Only 31.43\% (number of subjects $=22$ ) of the subject opted to indulge in any kind of argument if above status message was posted by any of their 'Non-Met' friend.

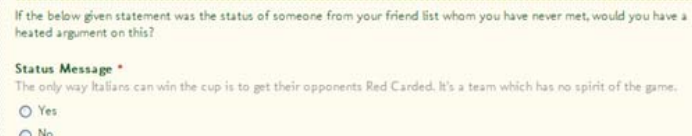

Figure 8. Screenshot of section 3

\section{ANALYSIS OF RESULTS AND DISCUSSIONS}

The survey results reveal that, as the level of flaming in a status messages rises beyond the median level on the Flaming Invective Scale, the number of users choosing that message as their status falls rapidly. The users' opinions as seen in the flames in their choice of status messages are also greatly situational. In situation 1, the case of a world sporting event and related to actions of specific individual, the respondents preferred a less flamed status message. It can be noted that only a small amount of respondents opted for moderately flamed status messages. In situation 2, the general notion of developed countries' stand on the global environment crisis seems to have a greater influence 
on the respondents with a larger majority opting for a hostile status message. This suggested that SNS users can post a highly flamed message when situation is not specific to actions of any individual.

The data also indicates that situation where subjects are less aware of or less interest in (Situation 1), they prefer less flamed message as compared to the situation where greater number of users connect them and see the implication on their own lives (Situation 2), they prefer high flamed messages. This can be explained by respondents opting for flaming as a tone to support their viewpoint.

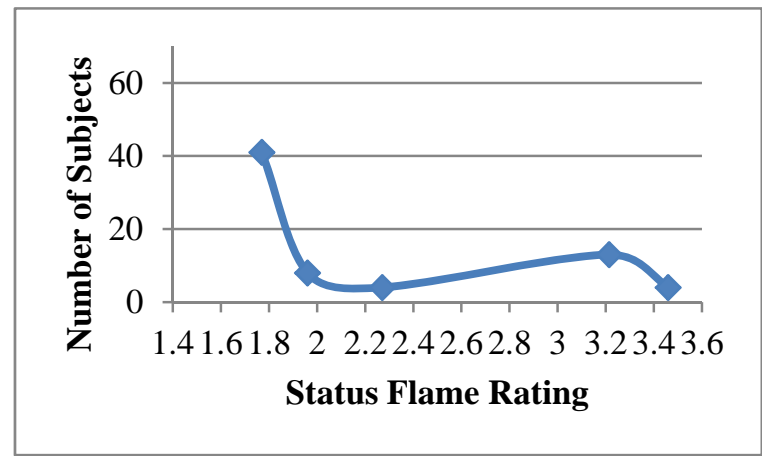

Figure 9. Number of Subjects Choosing a Status (Situation 1)

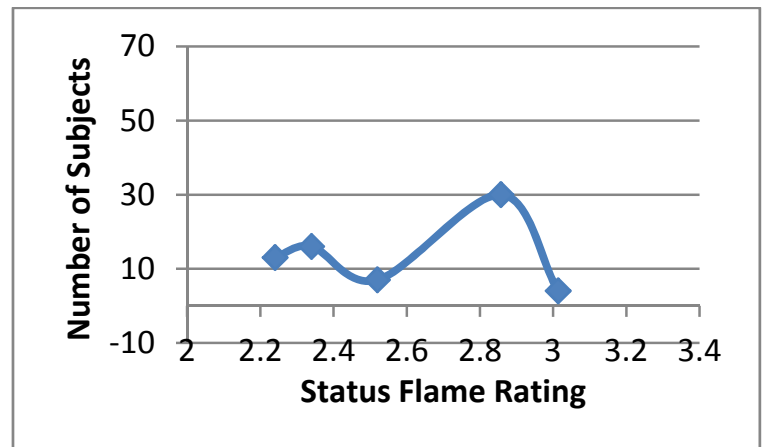

Figure 10. Number of Subjects Choosing a Status (Situation 2)

For messages in which subjects had an average flame rating of 3.182 (Section 3), only $31.43 \%$ of suggested that they would flame on comments to such status messages when posted by a 'Non-Met' user. Research suggests that respondents, as stated above, exercise more restraint with flaming on hostile status messages. Since people prefer moderately hostile statuses over non-hostile ones in certain situation and such statuses are not responded with flames by the larger majority, it could be debatable that such statuses is perhaps accepted as normal and not as considered unacceptable by SNS users. The possible reason of such behavior can be existence of close friends, colleagues or relatives that they met regularly, in person, and users do not want to have a wrong impression on them by posting a highly flamed message or by responding to one.

\section{LIMITATIONS AND SUGGESTIONS FOR FURTHER RESEARCH}

This study has several limitations. The number of subjects was 70 whereas SNSs like, MySpace and Facebook has about 66 million to 500 million users [46]. In addition, though the research was conducted with a population as random as possible, but it can be noted that majority of the respondents were between the age group of 20-30 years, who may respond differently than middle aged or older respondents. We have just considered two global situations. There could be a possibility that some of the respondents are indifferent to one or more of these situations and hence consider all statuses relating to the same as 'non-hostile', 'moderately hostile' or 'hostile' based on wordings of the status. The response to a hostile status message when posted by a 'Non-Met' user is only surveyed. The study did 
not include the responses of close friends, acquaintances, rival factions, people of different age groups, celebrities, etc.

Further research can be conducted about the psychological reasons behind such behavioral tendencies. Different ethnic groups or populations of various countries, regions, etc can be studied. This is suggested as it has been observed that populations of some countries form a greater share of users on these SNSs than others. Studies based on age groups, gender, cultural and ethnic backgrounds with respect to their responses and behavioral tendencies can be conducted. Flaming hotspots and their respective implementation of content filters to control them on SNSs can be researched. Groups and pages, which have ardent supporters or vicious critics, are hotspots for flaming. These hotspots can be narrowed down with the help of in-site surveys or tracking reports from end-users.

\section{CONCLUSION}

This research concludes that generally SNS users' tend to restrain themselves from responding to the highly famed messages. When faced with flames in status messages or comments, only about a third of users agreed that they would tend to use flames. The research also revealed that people preferred flamed statuses for their own status but only up to a certain median level of flaming. This indicates that SNS users' are aware about their social reputation and even though they might want to flame but they prefer to avoid or use a moderately flamed message.

These finding will help researchers understand that even though CMC have more chances of flaming as compare to face-to-face communication, more use of SNS will lessen the chances of flaming and will provide a better environment for users from different socio-cultural backgrounds. Further, this study can be help researchers in developing the better automated content filter that will help in preventing flaming in the SNS.

\section{REFERENCES}

1. Aiken M, Waller B (2000). Flaming among first-time group support system users. Information \& Management, 37, 95-100.

2. Alonzo M, Aiken M (2004). Flaming in electronic communication. Decision Support Systems, 36, 204-213.

3. Bernthal K (1995). Online transmission of inflammatory remarks. PC Novice, 6, 39-40.

4. Boyd dm, Ellison, NB (2007). Social network sites: definition, history, and scholarship. Journal of ComputerMediated Communication, 13(1), article 11.

5. Bruce A. Reinig, Roberto J. Mejias (2004). The Effects of National Culture and anonymity on flaming and criticalness in GSS-supported discussions.

6. Chapman G (1995). Flamers. The New Republic, 13.

7. Cherny L (1995), The MUD register: Conversational modes of action in a text-based virtual reality. Linguistics Department. Palo Alto, CA: Stanford University.

8. Dvorak, J. C. (1994). The flaming of Madison Ave. Marketing Computers, 14, 22.

9. ECAR Research Study 8, 2008. Social networking sites, Student and Information Technology.

10. Ellison, NB, Steinfield C, Lampe C (2007). The benefits of Facebook "friends:" Social capital and college students' use of online social network sites. Journal of Computer Mediated Communication, 12(4), article 1.

11. Eveland JD, Bikson TK (1988). Work group structures and computer support: A field experiment, Transactions on Office Information Systems, 6, 354-37.

12. Festinger, L., Pepitone, A., \& Newcomb, T. (1952). Some consequences of de-individuation in a group. Journal of Abnormal and Social Psychology, 47, 382-389.

13. Friedman RA, Currall SC (2003). Conflict escalation: dispute exacerbating elements of e-mail communication conflict. Human Relations, 56 (11), 1325-1347.

14. Goodwin C, Heritage J (1990). Conversation analysis, Annual Review of Anthropology, 19, 283-307.

15. Harrison TM, Falvey L (2002). Democracy and new communication technologies. Communication Yearbook, 25, 1-33.

16. Hinds P, Kiesler S (1995). Communication across boundaries: Work, structure, and use of communication technologies in a large organization. Organization Science, 6, 373-393.

17. Horrigan J, Boase J, Rainie L, Wellman B (2006). The Strength of Internet Ties, Pew Internet \& American Life Project report. 
Volume XII, No. 1, pp. 425-435, 2011

18. Huber, GP (1990). A theory of the effects of advanced information technologies on organizational design, intelligence, and decision making. J. Fulk \& C. W. Steinfield (Eds.) Organizations and communication technologies, Sage, 237-274.

19. Joseph Kayany M. (1998).Contexts of Uninhibited Online Behavior: Flaming in Social Newsgroups on Usenet.

20. Kiesler S, Siegel J, McGuire, T (1984). Social psychological aspects of computer-mediated communication,. American Psychologist, 39 (10), 1123-1134.

21. Kitchens F (1998). Flaming in electronic media. Proceedings of the 29th Annual Conference of the Southwest Decision Sciences Institute, Atlanta, Georgia, 41- 45.

22. Lampe C, Ellison N, Steinfield C, (2006). A Face (book) in the crowd: social searching vs. social browsing,. Proceedings of the 20th Anniversary Conference on Computer Supported Cooperative Work ACM Press, 167170.

23. Landry EM (2000). Scrolling around the new organization: The potential for conflict in the on-line environment. Negotiation Journal, 16 (2), 133-142.

24. Lea, M., O'Shea, T., Fung, P., \& Spears, R. (1992). "Flaming” in computer-mediated communication: Observations, explanations, implications.

25. Mantovani G (1996). New communication environments: from everyday to virtual. London: Taylor \& Francis.

26. Markus ML (1994). Finding a happy medium: Explaining the negative effects of electronic communication on social life at work. ACM Transactions on Information Systems, 12 (2), 119-149.

27. Mauri C, 1992. Flaming: The Relationship between Social context cues and uninhibited verbal behaviour in computer-mediated communication.

28. McKenna K, Bargh JA (2000). Plan 9 from cyberspace: the implications of the Internet for personality and social psychology. Personality and Social Psychology Review, 4, 57-75.

29. Menninger K, Mayman M, Pruyser P (1963). The vital balance: the life process in mental health and illness. Viking, New York.

30. Moore DA, Kurtzberg TR, Thompson LL, Morris MW (1999). Long and short routes to success in electronically mediated negotiations: Group affiliations and good vibrations, Organizational Behavior and Human Decision Processes, 77 (1), 22-43.

31. Moor, P. J. (2007). Conforming to the flaming norm in the online commenting situation.

32. Norman A. Johnson, Randolph B. Cooper, Wynne W. Chin (2008). The effect of flaming on computermediated negotiations. European Journal of Information Systems 17, 417-434.

33. O'Sullivan PB, Flanagin AJ (2003). Reconceptualizing "flaming" and other problematic messages. New Media \& Society, 5 (1), 69-94.

34. Pinsonneault A, Heppel N (1998). Anonymity in group support systems research: a new conceptualization, measures, and contingency framework. Journal of Management Information Systems, 14 (3), 89-108.

35. Reinig B, Briggs R, Nunamaker J (1998). Flaming in the electronic classroom. Journal of Management Information Systems, 14 (3), 45-59.

36. Rheingold T, personal, communication, August 2, 2007.

37. Schrage, M (1997). Mr. Bozo, meet Miss Courtesy Worm. Computerworld, 31, 37.

38. Seabrook, J (1994). My first flame. The New Yorker, 70, 70-99.

39. Siegel J, Dubrovsky V, Kiesler S, McGuire TW (1986) Group processes in computer-mediated communication, Organizational Behavior and Human Decision Processes, 37, 157-187.

40. Stewart D (1991). Flame throwers: Why the heated bursts on your computer network? Omni, 13, 26.

41. Tamosaitis N (1991). Getting flamed isn't funny. Computer Life, 1, 207-208.

42. Turnage AK (2007). Email flaming behaviors and organizational conflict. Journal of Computer-Mediated Communication, 13(1), article 3.

43. Walther JB, Anderson JF, Park DW (1994), Interpersonal effects in computer-mediated interaction: A metaanalysis of social and antisocial communication. Communication Research, 460-487.

44. Walther JB (1995). Relational aspects of computer-mediated communication: Experimental observations over time. Organization Science, 6 (2), 186-203.

45. Wellman B, Salaff J, Dimitrova D, Garton L, Gulia, M, Haythornthwaite, C (1996). Computer networks as social networks: collaborative work, telework, and virtual community. Annual Review of Sociology, 22, 213238.

46. Zuckerburg M (2010-07-21). “500 million stories”. Available: http://blog.facebook.com/blog.php?post=409753352130. 